Введение. Триптофран - незаменимая аминокислота, которая содержится в основном в белковой пище и его доступность во многом зависит от рациона питания. Значительная часть триптофрана метаболизируется в желудочно-кишечном тракте микробиотой кишечника, образуя ряд биологически активных молекул, включая лиганды арилуглеводородного рецептора, кинуренины, серотонин (5-гидрокситриптамин).

Цель исследования. Провести анализ научных исследований, подтверждающих ключевую роль микробных катаболитов триптофрана на фрункции макроорганизма.

Материал и методы. Проведен анализ 47 англоязычных источников литературы, содержащих информацию об эффректах метаболитов триптофрана на организм млекопитающих.

Результаты. Установлено, что метаболизм триптофрана играет центральную роль как в нормальном макроорганизме, так и при патологических состояниях, прямо или косвенно контролируется микробиотой кишечника.

Выводы. Таким образом, метаболизм триптофрана представляет собой важнейшую терапевтическую мишень, которая недостаточно используется для коррекции ряда хронических неврологических патологий и иммунокомпетентных состояний. Важный фактор - использование микроорганизмами нутрицевтиков и пробиотиков, модулирующих метаболизм триптофрана в кишечнике и стимулирующих синтез специфрических метаболитов.

Ключевые слова: триптофан, аминокислоты, гомеостаз, кишечная микробиота

\title{
TRYPTOPHAN: A KEY METABOLITE OF HOMEOSTASIS AND A REGULATOR OF BODY FUNCTIONS ${ }^{1}$ V. M. Sheibak, ${ }^{2}$ A. Yu. Pauliukavets ${ }^{1}$ Grodno State Medical University, Grodno, Belarus ${ }^{2}$ Grodno Regional Center of Transfusiology, Grodno, Belarus
}

Background. Tryptophan is an essential amino acid found mainly in protein foods and its availability is highly dependent on a diet. A significant part of tryptophan is metabolized in the gastrointestinal tract by the intestinal microbiota, producing a number of biologically active molecules, including aryl hydrocarbon receptor ligands, kynurenines, and serotonin (5-hydroxytryptamine).

Objective. To analyze scientific studies confirming the key role of tryptophan microbial catabolites on the function of a macroorganism.

Material and methods. The analysis of 47 English-language literature sources containing information on the effects of tryptophan metabolites on the mammalian organism was carried out.

Results. It has been established that tryptophan metabolism plays a central role both in a normal macroorganism and in pathological conditions, it being directly or indirectly controlled by the intestinal microbiota.

Conclusions. Thus, tryptophan metabolism is an important therapeutic target, underutilized in the treatment of a number of chronic neurological pathologies and immunocompetent conditions. An important factor is the use of nutraceuticals and probiotics by microorganisms that modulate the metabolism of tryptophan in the intestine and stimulate the synthesis of specific metabolites.

Keywords: tryptophan, amino acids, homeostasis, intestinal microbiota

\section{Автор, ответственный за переписку:}

Шейбак Владимир Михайлович, д-р мед. наук, проф., Гродненский государственный медицинский университет; e-mail: VSheibak@gmail.com

Для цитирования: Шейбак, В. М. Триптофан: ключевой метаболит гомеостаза и регулятор функций организма / В. М. Шейбак, А. Ю. Павлюковец // Гепатология и гастроэнтерология. 2021. Т. 5, № 2. С. 143-149. https://doi.org /10.25298/2616-5546-2021-5-2-143-149
Corresponding author:

Sheibak Vladimir Mikhailovich, PhD, MD (Medicine), Professor, Grodno State Medical University; e-mail: VSheibak@gmail.com

For citation: Sheibak VM, Pauliukavets AYu. Tryptophan: a key metabolite of homeostasis and a regulator of body functions. Hepatology and Gastroenterology. 2021;5(2):143-149. https://doi.org/10.25298/2616-5546-2021-5-2-143-149 
Триптофан - незаменимая аминокислота, которая содержится в основном в белковой пище, его доступность во многом зависит от рациона питания. Содержание триптофрана в белках и плазме крови ниже, чем остальных 20 протеиногенных аминокислот [1]. Следовательно, доступность триптофана ниже, чем других аминокислот, он играет лимитирующую роль во время синтеза белка [2]. Кроме того, триптофан является сигнальной молекулой, которая регулирует синтез белка в печени, предшественником множества биологически активных соединений, включая серотонин, мелатонин, триптамин, хинолиновую кислоту и кинуреновую кислоту, предшественником коферментов никотинамидадениндинуклеотида и никотинамидадениндинуклеотидфосфрата (НАД и НАДФ) [3].

В статье представлен анализ научных исследований, указывающих на ключевую роль микробных катаболитов триптофана в функционировании макроорганизма.

Большая часть поступающего в организм триптофрана всасывается в тонком кишечнике [4]. При этом диета имеет решающее значение, поскольку одновременное поступление нейтральных и ароматических аминокислот (особенно валина, лейцина, изолейцина) ограничивает всасывание и доступность для организма этой аминокислоты. Прием углеводов снижает абсорбцию триптофрана, а развивающаяся гиперинсулинемия стимулирует захват нейтраль- ных аминокислот [5]. Попадая в кровь, триптофан на 80-90\% связывается с альбумином, что имеет значение для концентрации в плазме его свободной формы и последующего транспорта в ЦНС, поскольку альбумин - основной переносчик свободных жирных кислот и некоторых микроэлементов (цинк). Через гематоэнцефалический барьер (ГЭБ) триптофан переносится транспортером аминокислот L-типа (LAT1/Lat1), ответственным за транспорт больших нейтральных аминокислот [6]. Этот антипортер белкового комплекса экспрессируется в отростках астроцитов, которые включены в ГЭБ. Кроме того, транспортер экспрессируется нейронами, астроцитами и микроглией, которые составляют вторичный барьер для поглощения триптофана [7].

Значительная часть триптофана метаболизируется в желудочно-кишечном тракте микробиотой кишечника, образующей ряд биологически активных молекул, включая лиганды арилуглеводородного рецептора; а также кинуренины клетками иммунной системы и эпителиальными клетками кишечника. Скорость-лимитирующими ферментами в этих процессах является индоламин-2,3-диоксигеназа 1, а продукция серотонина (5-гидрокситриптамин) особенно интенсивно идет в энтерохромафффинных клетках с участием триптофрангидроксилазы 1 [8] (табл.).

Промежуточные и конечные метаболиты деградации триптофана влияют на гомеостаз организма, создавая метаболические оси ки-

Таблица. - Продукция метаболитов триптофана микробиомом кишечника

Table. - Production of tryptophan metabolites by the intestinal microbiome

\begin{tabular}{|c|c|}
\hline Метаболит & Продуценты \\
\hline Индол & $\begin{array}{l}\text { Bacteroides thetaiotaomicron, Bacteroides ovatus, Clostridium limosum, Clostridium bifermentans, Clostrid- } \\
\text { ium malenomenatum, Clostridium lentoputrescens, Clostridium tetani, Clostridium tetanomorphum, Clostrid- } \\
\text { ium ghoni, Clostridium sordellii, Desulfovibrio vulgaris, Enterococcus faecalis, Escherichia coli, Fusobacteri- } \\
\text { um nucleatum, Haemophilus influenza, Peptostreptococcus asscharolyticus, }\end{array}$ \\
\hline $\begin{array}{l}\text { 3-метилиндол } \\
\text { (Скатол) }\end{array}$ & $\begin{array}{l}\text { Bacteroides thetaiotaomicron, Butyrivibrio fibrisolvens, Clostridium bartlettii, Clostridium scatologenes, Clos- } \\
\text { tridium drakei, Eubacterium cylindroides, Eubacterium rectale, Lactobacillus spp., Megamonas hypermegale, }\end{array}$ \\
\hline $\begin{array}{l}\text { Индолуксусная } \\
\text { кислота (ИУК) }\end{array}$ & $\begin{array}{l}\text { Bacteroides thetaiotaomicron, Bacteroides eggerthii, Bacteroides ovatus, Bacteroides fragilis, Bifidobac- } \\
\text { terium adolescentis, Bifidobacterium longum subsp. Longum, Bifidobacterium pseudolongum, Clostridium } \\
\text { bartlettii, Clostridium difficile, Clostridium lituseburense, Clostridium paraputrificum, Clostridium perfrin- } \\
\text { gens,Clostridium putrefaciens, Clostridium saccharolyticum, Clostridium sticklandii, Clostridium subtermina- } \\
\text { le,Escherichia coli, Eubacterium hallii,Eubacterium cylindroides, Parabacteroides distasonis, Peptostrepto- } \\
\text { coccus asscharolyticus }\end{array}$ \\
\hline $\begin{array}{l}\text { Индолакриловая } \\
\text { кислота }\end{array}$ & $\begin{array}{l}\text { Clostridium sporogenes, Peptostreptococcus russellii, Peptostreptococcus anaerobius, Peptostreptococcus } \\
\text { stomatis }\end{array}$ \\
\hline Индолеальдегид & Lactobacillus acidophilus, Lactobacillus murinus, Lactobacillus reuteri \\
\hline $\begin{array}{l}\text { Индолмолочная } \\
\text { кислота }\end{array}$ & $\begin{array}{l}\text { Anaerostipes hadrus, Anaerostipes caccae, Bacteroides thetaiotaomicron, Bacteroides eggerthii, Bacte- } \\
\text { roides ovatus, Bacteroides fragilis, Bifidobacterium adolescentis, Bifidobacterium bifidum, Bifidobacterium } \\
\text { longum subsp. Infantis, Bifidobacterium longum subsp. Longum, Bifidobacterium pseudolongum, Clostrid- } \\
\text { ium bartlettii, Clostridium perfringens, Clostridium sporogenes, Clostridium saccharolyticum, Escherichia } \\
\text { coli,Eubacterium rectale, Eubacterium cylindroides, Faecalibacterium prausnitzii ,Lactobacillus murinus, } \\
\text { Lactobacillus paracasei, Lactobacillus reuteri, Megamonas hypermegale, Parabacteroides distasonis, Pep- } \\
\text { tostreptococcus asscharolyticu }\end{array}$ \\
\hline $\begin{array}{l}\text { Индолпропионовая } \\
\text { кислота }\end{array}$ & $\begin{array}{l}\text { Clostridium botulinum, Clostridium caloritolerans, Clostridium paraputrificum, Clostridium sporogenes, Clos- } \\
\text { tridium cadvareris, Peptostreptococcus asscharolyticus, Peptostreptococcus russellii, Peptostreptococcus } \\
\text { anaerobius, Peptostreptococcus stomatis }\end{array}$ \\
\hline Триптамин & Clostridium porogenes, Ruminococcus gnavus \\
\hline $\begin{array}{l}\text { Никотиновая } \\
\text { кислота }\end{array}$ & $\begin{array}{l}\text { Escherichia coli, Saccharomyces cerevisiae, Bacteroides fragilis, Prevotella copri, Ruminococcus lactaris, } \\
\text { Bifidobacterium infantis, Helicobacter pylori, Fusobacterium varium }\end{array}$ \\
\hline
\end{tabular}


шечник-печень и кишечник-мозг, поскольку они абсорбируются через базолатеральную мембрану эпителия кишечника и попадают в кровоток [9, 10]. Примерная схема метаболизма триптофрана в кишечнике млекопитающих представлена на рисунке.

Триптофан служит единственным субстратом для синтеза биогенного амина серотонина, который образуется преимущественно в дистальных отделах желудочно-кишечного тракта (90\%) и в меньшей степени - в ЦНС (10\%) [9]. Триптофрангидроксилаза катализирует начальную, скорость-лимитирующую стадию превращения триптофрана в серотонин. Энтерохромаффинные клетки кишечника экспрессируют триптофангидроксилазу 1 (КФ 1.14.16.4), в то время как серотонинергические нейроны ЦНС и кишечной нервной системы экспрессируют триптофрангидроксилазу 2 (КФ 1.14.16.5). Эти фрерменты превращают триптофан в 5-гидрокситриптофан, а декарбоксилаза ароматических аминокислот превращает 5-гидрокситриптофан в 5-гидрокситриптамин или серотонин. Энтерохромаффинные клетки слизистой оболочки кишечника синтезируют подавляющее большинство серотонина в организме. При активации энтерохромаффринных клеток серотонин связывается нервными окончаниями внутренних сенсорных нейронов блуждающего нерва, что позволяет инициировать ответные реакции со стороны нервных центров и гипоталамуса [11].

Тромбоциты, циркулирующие в капиллярной сети собственной пластинки, поглощают оставшийся серотонин посредством селективного обратного захвата серотонина. Эти клетки служат системным резервуаром серотонина и могут доставлять его в периферические ткани. В эпи- физе серотонин в дальнейшем может быть преобразован в мелатонин, основной эндогенный регулятор множества метаболических процессов, инициации сна и циркадных ритмов. Серотонин катаболизируется моноаминоксидазой до 5-гидроксииндолацетальдегида, а затем альдегиддегидрогеназой до 5-гидроксииндолуксусной кислоты, которая выводится с мочой [12].

Серотонинергические нейроны кишечника составляют примерно 2\% всех кишечных нейронов. Эти нейроны обычно образуют синаптические связи с другими серотонинергическими нейронами, где на них приходится около 10\% общей возбуждающей активности, и которые в совокупности регулируют моторику кишечника [13].

Серотонин вместе с холецистокинином участвует в регуляции функции толстого и тонкого кишечника, в первую очередь за счет своего действия на рецепторы 5-гидрокситриптамина $4[13,14]$. Кроме того, серотонин играет важную роль в секреции хлорид- и бикарбонат-анионов, нейтрализуя содержимое просвета кишечника и защищая эпителиальные клетки от просветных паразитов. Серотонин также может активировать секрецию кишечных эпителиальных клеток за счет паракринного действия. Активация рецепторов 5-гидрокситриптамина 3 и 4, связанная с серотонином, одновременно стимулирует локальный нейрональный вазодилататорный ответ [14].

Интерстициальные клетки Кахаля представляют собой широко распространенные «водители ритма», регулирующие спонтанную ритмическую моторику кишечника. Серотонин посредством воздействия на рецептор 5-гидрокситриптамина 2В способствует сохранению сети интерстициальных клеток Кахаля. У мышей с дефицитом рецептора 5-гидрокситриптамина 2B

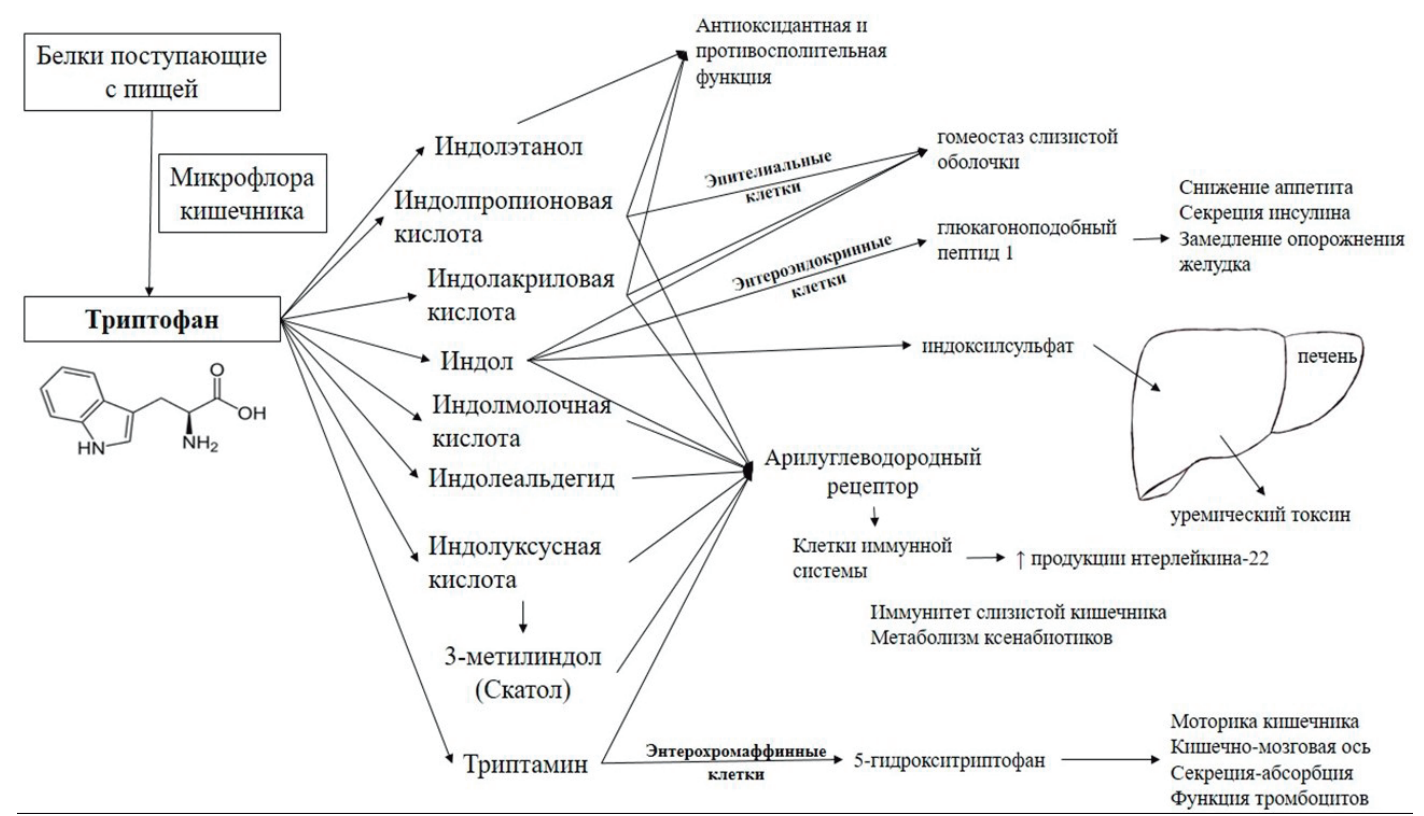

Рисунок. - Микробные метаболиты триптофрана и функции систем организма

Figure-Microbial metabolites of tryptophan and body system functions 
обнаруживают повышенную плотность интерстициальных клеток Кахаля и нарушение спонтанной ритмической моторики кишечника [15].

Серотонин также стимулирует окончания блуждающего нерва в верхних отделах желудочно-кишечного тракта, экспрессирующих рецептор 5-гидрокситриптамина 3 в зависимости от поступающих нутриентов. Так, инфузия в кишечник глюкозы вызывает высвобождение серотонина из депо энтерохромаффринных клеток, стимуляцию окончаний блуждающего нерва, что ведет к торможению опорожнения желудка и активирует секрецию инсулина поджелудочной железой.

Инфузия липидов способствует циклин-зависимому замедлению вагусной передачи сигналов и повышенному потреблению пищи [16]. Активация парасимпатических нейронов вызывает повышение циркулирующего серотонина [17].

Примерно 90\% триптофрана катаболизируется в печени по кинурениновому пути, где локализован ключевой фермент триптофан-2,3-диоксигеназа. Провоспалительные цитокины, в частности интерферон-ү, стимулируют активность фермента, в то время как глюкокортикоиды индуцируют экспрессию триптофран-2,3-диоксигеназы. Далее кинуренин катаболизируется до двух провоспалительных нейроактивных медиаторов - кинуреновой и хинолиновой кислот. Хинолиновая кислота далее катаболизируется в ниацин и НАД+ [18].

Центральные кинурениновые катаболиты образуются локально и в минимальной степени проникают через ГЭБ. В головном мозге они действуют на нейрональные рецепторы N-метил-D-аспартата, постсинаптические рецепторы, активируемые глутаматом, которые важны для обучения и памяти, сверхактивируются в случае нейрональной эксайтотоксичности. Кинурениновая кислота действует как антагонист рецептора N-метил-D-аспартата в сайте связывания глицина и обычно рассматривается как нейропротекторный фактор при фризиологических концентрациях, в то время как хинолиновая кислота, продуцируемая в основном в микроглии, действует как слабый агонист и является нейротоксичным соединением, одновременно усиливающим свободно-радикальное окисление [18]. Кинурениновая кислота также сильный антагонист а7-никотиновых рецепторов.

Хотя большая часть потребляемого белка расщепляется и всасывается в тонком кишечнике [5], значительное количество белков и аминокислот (6-18 г/день) могут достигать толстого кишечника [6], где их утилизируют различные комменсальные бактерии (табл. 1). Бактериальный катаболизм белка повышается с увеличением его потребления, при дефиците неперевариваемых углеводов в толстом кишечнике, увеличении просветного рН [7]. Постепенное истощение углеводных субстратов, наблюдаемое от проксимального к дистальному отделу толстой кишки, вызывает сдвиг бактериального катаболизма с сахаролитической ферментации на протеолитическую [9]. В соответствии с этим концентрации фенольных соединений в результате разложения ароматических аминокислот в содержимом кишечника человека более чем в четыре раза выше в дистальном отделе толстой кишки, чем в проксимальном отделе толстой кишки [18].

Хотя продукты деградации бактериального белка в целом считаются вредными для хозяина, катаболиты триптофрана, генерируемые микробиотой кишечника, вносят важный вклад в гомеостаз не только кишечника, но всего организма [4].

Показано, что различия в видовом и количественном составе микробиома кишечника могут влиять на доступность триптофана. У безмикробных мышей наблюдаются повышенные уровни триптофрана и серотонина в плазме, которые нормализуются после восстановления кишечной микробиоты [4]. Отсутствие микроорганизмов в кишечнике мышей снижает кишечный катаболизм триптофрана по кинурениновому пути, что приводит к повышению его уровня в плазме крови с одновременным снижением содержания кинуренина.

Подтверждая наличие оси кишечник-мозг, у крыс, получавших пробиотик Bifidobacterium infantis, наблюдалось снижение уровня 5-гидроксииндолуксусной кислоты в кортикальном слое головного мозга и заметное увеличение циркулирующих кинуренина и триптофрана. Введение крысам Lactobacillus johnsonii приводило к снижению концентраций кинуренина и активности 2,3-индоламиндиоксигеназ в эпителиальных клетках кишечника, вероятно, из-за продукции L. johnsonii перекиси водорода, оказывающей ингибирующий эффрект на 2,3-индоламиндиоксигеназу [19]. Кроме того, эпителиальные клетки могут изменять состав микробиома кишечника путем производства и секреции бактериотоксичных метаболитов кинуренина [20].

Некоторые таксоны бактерий напрямую используют триптофан, экспрессируя фермент триптофраназу, который превращает триптофан в индол. Повышенная метаболическая активность в отношении триптофана показана у Actinobacteria, Firmicutes, Bacteroidetes, Proteobacteria и Fusobacteria, а также у родов Clostridium, Burkholderia, Streptomyces, Pseudomonas и Bacillus [21]. Индол и его последующие метаболиты индол-3-ацетат и триптамин, снижают выраженность воспаления в эпителиальных клетках кишечника и провоспалительную активность макрофагов [22]. Ряд других родов, включая Clostridium, Ruminococcus, Blautia и Lactobacillus, экспрессирующих декарбоксилазы ароматических аминокислот, катаболизируют триптофран до триптамина [21]. 
Многие производные индола, такие как индол-3-альдегид, индол-3-уксусная кислота, индол-3-пропионовая кислота, индол-3-ацетальдегид и индолакриловая кислота, являются лигандами для рецепторов ароматических углеводородов. Передача сигналов рецепторами ароматических углеводородов считается ключевым компонентом иммунного ответа на уровне кишечного барьера и, таким образом, имеет решающее значение для гомеостаза кишечника, модулируя регенерацию эпителия, целостность кишечного барьера и экспансию многих типов иммунных клеток, таких как интраэпителиальные лимфоциты, Т-хелперы-17, лимфоидные клетки, макрофраги, дендритные клетки и нейтрофилы [25].

Рецептор ароматических углеводородов напрямую активируется нутриентами и ксенобиотиками. Многие лиганды рецептора ароматических углеводородов метаболизируются и инактивируются белками семейства цитохрома P450, такими как Сур1А1 [13].

Катаболиты триптофрана, генерируемые микробиотой кишечника, - важные сигнальные молекулы в микробных сообществах, а также во взаимодействии между макроорганизмом и микробиомом, могут поддерживать кишечный и системный гомеостаз. Так, индол - межклеточная сигнальная молекула, которая важна для микробных популяций, влияет на образование спор, стабильность плазмид, устойчивость к антибиотикам, образование биопленок и вирулентность [24]. Индолэтанол проявляет антимикробную активность в отношении Staphylococcus aureus, Salmonella enterica $и$ Lactobacillus plantarum [25, 26]. Индолэтанол также подавляет репликацию бактериофага термофильной бактерии Geobacillus sp. E263. Индол-3-ацетат обладает противогрибковой активностью против штаммов Penicillium и антибактериальной активностью против E. coli и B. cereus [27, 28]. Более того, существуют доказательства, подтверждающие, что индолы влияют на выживание нематод Caenorhabditis elegans [29, 30]. Таким образом, индолы играют роль модуляторов микробных сообществ кишечника во всех царствах, включая бактерии, грибы и вирусы.

Производные индола улучшают барьерные функции кишечника за счет увеличения экспрессии генов, участвующих в поддержании клеточной структуры белками плотных соединений [31, 32]. Индолпропионовая кислота является лигандом для сенсора ксенобиотиков, рецептора прегнана X [33]. Показано, что индолпропионовая кислота снижает проницаемость кишечника у мышей, получавших рацион с высоким содержанием жиров [34]. Индолакриловая кислота уменьшает воспалительные реакции, способствует диффреренцировке бокаловидных клеток и продукции муцина [15].
Индол модулирует секрецию глюкагоноподобного пептида-1 (GLP-1) энтероэндокринными L клетками толстой кишки [35]. GLP-1 необходим для стимуляции секреции инсулина $\beta$-клетками поджелудочной железы, подавления аппетита и замедления опорожнения желудка [36]. Более высокие концентрации индолпропионовой кислоты в сыворотке коррелируют со снижением риска развития диабета 2 типа и секрецией инсулина, что указывает на предполагаемую роль индолов в модуляции метаболизма глюкозы.

Триптамин, катаболит триптофана, продуцируемый C. sporogenes и Ruminococcus gnavus, представляет собой нейротрансмиттер кишечных нейронов [37]. Триптамин может выступать в качестве сигнальной молекулы, которая влияет на время транзита по кишечнику, что тесно связано с кишечной микробной композицией, ее разнообразием и метаболизмом в организме человека [23]. R. gnavus - распространенный вид кишечной микробиоты, обнаруживаемый примерно у $90 \%$ взрослых и младенцев, способность этого вида вырабатывать триптамин может иметь большое значение для макроорганизма [38, 39].

Анализ ассоциации между микробиомом кишечника человека и реакциями цитокинов ех vivo в цельной крови на микробную стимуляцию выявил отрицательную связь между производством интерферона-ү и бактериальными генами, ответственными за превращение триптофана в индолэтанол, что позволяет предположить, что индолэтанол обладает противовоспалительными свойствами [40].

Индолпропионовая кислота - скэвенджер гидроксильных радикалов [41]. Индол-3-уксусная кислота и триптамин ослабляли секрецию провоспалительных цитокинов в культурах макрофагов мышей и культурах гепатоцитов рецептор-зависимым образом, предполагая, что микробные катаболиты триптофрана также могут влиять на воспалительные реакции в печени [8]. Эффректы катаболитов триптофрана на продукцию цитокинов могут зависеть от активации арилуглеводородных рецепторов, поскольку было показано, что передача сигналов через арилуглеводородный рецептор модифицирует ответы, инициируемые toll-подобным рецептором в дендритных клетках человека [42, 43].

Хотя индолы в целом оказывают положительное действие, исключением является индоксилсульфат, ко-метаболит макроорганизма и микробов, образуемый из индола в печени под действием ферментов цитохрома Р450, включая CYP2E1 и сульфотрансферазы [44]. Этот метаболит обычно характеризуется как уремический токсин, который накапливается у пациентов с хроническим поражением почек [45]. Индоксилсульфат - мощный агонист арилуглеводородных рецепторов, вызывает тубулоинтерстициальный фиброз, гломерулярный склероз, 
дисфункцию эндотелиальных клеток сосудов и окислительный стресс в эндотелиальных клетках [46]. Индоксилсульфрат не обнаруживается у стерильных мышей, поскольку производство индоксилсульфата зависит от комменсальных бактерий [47]. Манипуляции с микробным катаболизмом триптофрана в кишечнике могут быть одной из стратегий снижения циркулирующих уровней индоксилсульфата [47].

\section{Выводы}

Таким образом, метаболизм триптофрана играет центральную роль как в здоровом макро- организме, так и при патологических состояниях, прямо или косвенно контролируется микробиотой кишечника и представляет собой важнейшую терапевтическую мишень, которая недостаточно используется для коррекции ряда хронических неврологических патологий и иммунокомпетентных состояний. Важным фрактором является использование микроорганизмами нутрицевтиков и пробиотиков, модулирующих метаболизм триптофана в кишечнике и стимулирующих синтез специфических метаболитов.

\section{References}

1. Reilly JG, McTavish SF, Young AH. Rapid depletion of plasma tryptophan: A review of studies and experimental methodology. J Psychopharmacol. 1997;11:381-392. doi: 10.1177/026988119701100416.

2. Mariotti F, Gardner CD. Dietary Protein and Amino Acids in Vegetarian Diets - A Review. Nutrients. 2019;11:2661. doi: 10.3390/nu11112661.

3. Lesurtel M, Graf R, Aleil B, Walther DJ, Tian Y, Jochum W, Gachet C, Bader M, Clavien P-A. Platelet-derived serotonin mediates liver regeneration. Science. 2006;312:104-107. doi: 10.1126/science.1123842.

4. Nyangale EP, Mottram DS, Gibson GR. Gut microbial activity, implications for health and disease: the potential role of metabolite analysis. J Proteome Res. 2012;11:5573-5585. doi: $10.1021 /$ pr300637d.

5. Evenepoel P, Claus D, Geypens B, Hiele M, Geboes K, Rutgeerts $\mathrm{P}$, Ghooset $\mathrm{Y}$. Amount and fate of egg protein escaping assimilation in the small intestine of humans. Am J Physiol. 1999;277(5):G935-943. doi: 10.1152/ ajpgi.1999.277.5.G935.

6. Watson MD, Cross BL, Grosicki GJ. Evidence for the Contribution of Gut Microbiota to Age-Related Anabolic Resistance. Nutrients. 2021;13(2):706-727. doi: 10.3390/ nu13020706.

7. Macfarlane GT, Cummings JH, Macfarlane S, Gibson GR. Influence of retention time on degradation of pancreatic enzymes by human colonic bacteria grown in a 3-stage continuous culture system. J Appl Bacteriol. 1989;67:520527.

8. Krishnan S, Ding $Y$, Saedi N, Choi M, Sridharan GV Sherr DH, Yarmush ML, Alaniz RC, Jayaraman A, Lee K. Gut Microbiota-Derived Tryptophan Metabolites Modulate Inflammatory Response in Hepatocytes and Macrophages. Cell Rep. 2018;23(4):1099-1111. doi: 10.1016/j. celrep.2018.03.109.

9. Roager HM, Hansen LBS, Bahl MI, Frandsen HL, Carvalho V, Gøbel RJ, Dalgaard MD, Plichta DR, Sparholt MH, Vestergaard H, Hansen T, Sicheritz-Pontén T, Nielsen HB Pedersen O, Lauritzen L, Kristensen M, Gupta R, Licht TR. Colonic transit time is related to bacterial metabolism and mucosal turnover in the gut. Nat Microbiol. 2016;1:16093. doi: 10.1038/nmicrobiol.2016.93.

10. Pavlova T, Vidova V, Bienertova-Vasku J, Janku P, Almasi M, Klanova J, Spacil Z. Urinary intermediates of tryptophan as indicators of the gut microbial metabolism. Anal Chim Acta. 2017;987:72-80. doi: 10.1016/j.aca.2017.08.022.

11. Dou L, Bertrand E, Cerini C, Faure V, Sampol J, Vanholder $R$, Berland $Y$, Brunet $P$. The uremic solutes $p$-cresol and indoxyl sulfate inhibit endothelial proliferation and wound repair. Kidney Int. 2004;65(2):442-451. doi: 10.1111/j.15231755.2004.00399.x.

12. Geypens B, Claus D, Evenepoel P, Hiele M, Maes B, Peeters $M$, Rutgeerts $P$, Ghoos $Y$. Influence of dietary protein supplements on the formation of bacterial metabolites in the colon. Gut. 1997:41(1):70-76. doi: 10.1136/gut.41.1.70

13. Lee JH, Lee J. Indole as an intercellular signal in microbial communities. FEMS Microbiol Rev. 2010;34:426-444.
14. Dodd D, Spitzer MH, Van Treuren W, Merrill BD, Hryckowian AJ, Higginbottom SK, Le A, Cowan TM, Nolan GP, Fischbach MA, Sonnenburg JL. A gut bacterial pathway metabolizes aromatic amino acids into nine circulating metabolites. Nature. 2017;551(7682):648-652. doi: $10.1038 /$ nature24661.

15. Wlodarska M, Luo C, Kolde R, d'Hennezel E, Annand JW, Heim CE, Krastel P, Schmitt EK, Omar AS, Creasey EA, Garner AL, Mohammadi S, O'Connell DJ, Abubucker S, Arthur TD, Franzosa EA, Huttenhower C, Murphy LO, Haiser HJ, Vlamakis H, Porter JA, Xavier RJ. Indoleacrylic Acid Produced by Commensal Peptostreptococcus Species Suppresses Inflammation. Cell Host Microbe. 2017;22(1):25-37. doi: 10.1016/j.chom.2017.06.007.

16. Cervantes-Barragan L, Chai JN, Tianero MD, Di Luccia B, Ahern PP, Merriman J, Cortez VS, Caparon MG, Donia MS, Gilfillan S, Cella M, Gordon JI, Hsieh C-S, Colonna M. Lactobacillus reuteri induces gut intraepithelial CD4+CD8aa+ T cells. Science. 2017;357(6353):806-810. doi: 10.1126/science.aah5825.

17. Wilck N, Matus MG, Kearney SM, Olesen SW, Forslund K, Bartolomaeus $\mathrm{H}$, Haase S, Mähler A, Balogh A, Markó L, Vvedenskaya O, Kleiner FH, Tsvetkov D, Klug L, Costea PI, Sunagawa S, Maier L, Rakova N, Schatz V, Neubert P, Frätzer C, Krannich A, Gollasch M, Grohme DA, Côrte-Real $\mathrm{BF}$, et al. Salt-responsive gut commensal modulates $\mathrm{TH} 17$ axis and disease. Nature. 2017;551:585-589. doi: 10.1038/ nature24628.

18. Smith EA, Macfarlane GT. Enumeration of human colonic bacteria producing phenolic and indolic compounds: effects of $\mathrm{pH}$, carbohydrate availability and retention time on dissimilatory aromatic amino acid metabolism. $J$ Appl Bacteriol. 1996;81(3):288-302. doi: 10.1111/j.13652672.1996.tb04331.x.

19. Abildgaard A, Elfving B, Hokland M, Wegener G, Lund S. The microbial metabolite indole-3-propionic acid improves glucose metabolism in rats, but does not affect behaviour. Arch Physiol Biochem. 2018;124(4):306-312. doi: 10.1080/13813455.2017.1398262.

20. Reimann F, Tolhurst G, Gribble FM. G-Protein-Coupled Receptors in Intestinal Chemosensation. Cell Metab. 2012;15(4):421-431. doi: 10.1016/j.cmet.2011.12.019.

21. Koopman N, Katsavelis D, ten Hove AS, Brul S, de Jonge WJ, Seppen J. The Multifaceted Role of Serotonin in Intestinal Homeostasis. Int J Mol Sci. 2021;22(17):9487. doi: $10.3390 / \mathrm{ijms} 22179487$

22. Mawe GM, Hoffman JM. Serotonin signalling in the gutfunctions, dysfunctions and therapeutic targets. Nat Rev Gastroenterol Hepatol. 2013;10(10):473-486. doi: 10.1038/ nrgastro.2013.105

23. Wandeputte D, Falony G, Vieira-Silva S, Tito RY, Joossens $\mathrm{M}$, Raes J. Stool consistency is strongly associated with gut microbiota richness and composition, enterotypes and bacterial growth rates. Gut. 2016;65:57-62. doi: 10.1136/ gutjnl-2015-309618.

24. Chen H, Fink GR. Feedback control of morphogenesis in fungi by aromatic alcohols. Genes Dev. 2006;20(9):11501161. doi: $10.1101 / \mathrm{gad} .1411806$. 
25. Elleuch L, Shaaban M, Smaoui S, Mellouli L, Karray-Reba I, Fourati-Ben Fguira L, Shaaban KA, Laatsch H. Bioactive secondary metabolites from a new terrestrial Streptomyces sp. TN262. Appl Biochem Biotechnol. 2010;162(2):579593. doi: 10.1007/s12010-009-8808-4.

26. Jin M, Xu C, Zhang X. The effect of tryptophol on the bacteriophage infection in high-temperature environment. App Microbiol Biotechnol. 2015;99(19):8101-8111. doi: 10.1007/ s00253-015-6674-2.

27. Honoré $A H$, Aunsbjerg SD, Ebrahimi $P$, Thorsen $M$, Benfeldt C, Knøchel S, Skov T. Metabolic footprinting for investigation of antifungal properties of Lactobacillus paracasei. Anal Bioanal Chem. 2016;408(1):83-96. doi: 10.1007/ s00216-015-9103-6.

28. Narayanan TK, Rao GR. Beta-indoleethanol and beta-indolelactic acid production by Candida species: their antibacterial and autoantibiotic action. Antimicrob Agents Chemother. 1976;9(3):375-380. doi: 10.1128/AAC.9.3.375

29. Lee J-H, Kim Y-G, Kim M, Kim E, Choi H, Kim Y, Lee J. Indole-associated predator-prey interactions between the nematode Caenorhabditis elegans and bacteria. Environ Microbiol. 2017;19(5):1776-1790. doi: 10.1111/14622920.13649.

30. Bommarius $B$, Anyanful A, Izrayelit $\mathrm{Y}$, Bhatt $\mathrm{S}$, Cartwright $\mathrm{E}$, Wang W, Swimm AI, Benian GM, Schroeder FC, Kalman D. A family of indoles regulate virulence and Shiga toxin production in pathogenic E. coli. PLoS One. 2013;8(1):e54456. doi: 10.1371/journal.pone.0054456.

31. Bansal T, Alaniz, RC, Wood TK, Jayaraman A. The bacterial signal indole increases epithelial-cell tight-junction resistance and attenuates indicators of inflammation. Proc Natl Acad Sci. 2010;107(1):228-233. doi: 10.1073/ pnas.0906112107.

32. Shimada Y, Kinoshita M, Harada K, Mizutani M, Masahata $\mathrm{K}$, Kayama $\mathrm{H}$, Takeda K. Commensal bacteria-dependent indole production enhances epithelial barrier function in the colon. PLoS One. 2013;8(11):600-604. doi: 10.1371/journal.pone.0080604.

33. Venkatesh M, Mukherjee S, Wang H, Li H, Sun K, Beneche AP, Qiu Z, Maher L, Redinbo MR, Phillips RS, Fleet JC, Kortagere S, Mukherjee P, Fasano A, Le Ven J, Nicholson JK, Dumas ME, Khanna KM, Mani S. Symbiotic bacteria metabolites regulate gastrointestinal barrier function via the xenobiotic sensor PXR and Toll-like receptor 4. Immunity. 2014;41(2):296-310. doi: 10.1016/j.immuni.2014.06.014.

34. Jennis M, Cavanaugh CR, Leo GC, Mabus JR, Lenhard J, Hornby PJ. Microbiota-derived tryptophan indoles increase after gastric bypass surgery and reduce intestinal permeability in vitro and in vivo. Neurogastroenterol Motil. 2018;30(2):e13178. doi: 10.1111/nmo.13178.

35. Chimerel C, Emery E, Summers DK, Keyser U, Gribble FM, Reimann F. Bacterial metabolite indole modulates incretin secretion from intestinal enteroendocrine $L$ cells. Cell Rep. 2014:9(4):1202-1208 doi: 10.1016/j celrep.2014.10.032.

36. Holst JJ. The Physiology of Glucagon-like Peptide 1. Physiol Rev. 2007;87(4):1409-1439. doi: 0.1152/physrev.00034.2006.

37. Williams BB, Van Benschoten AH, Cimermancic $P$, Donia MS, Zimmermann M, Taketani M, Ishihara A, Kashyap

Конфрликт интересов. Авторы заявляют об отсутствии конфрликта интересов.

Финансирование. Исследование проведено без спонсорской поддержки.

Соответствие принципам этики. Исследование одобрено локальным этическим комитетом.

Сведения об авторах:

Шейбак Владимир Михайлович, д-р мед. наук, проф., Гродненский государственный медицинский университет, e-mail: VSheibak@gmail.com, ORCID: 0000-0001-6829-447X

Павлюковец Анастасия Юрьевна, канд. биол. наук, доц., Гродненский областной центр трансфузиологии, e-mail: anastasiayk@mail.ru, ORCID: 0000-0001-7995-5587
PC, Fraser JS, Fischbach MA. Discovery and characterization of gut microbiota decarboxylases that can produce the neurotransmitter tryptamine. Cell Host Microbe. 2014;16(4):495-503. doi: 10.1016/j.chom.2014.09.001.

38. Qin J, Li R, Raes J, Arumugam M, Burgdorf KS, Manichanh C, Nielsen T, Pons N, Levenez F, Yamada T, Mende DR, Li J, Xu J, Li S, Li D, Cao J, Wang B, Liang $H$, Zheng $H$, Xie Y, Tap J, Lepage P, Bertalan M, Batto J-M, Hansen T, et al. A human gut microbial gene catalogue established by metagenomic sequencing. Nature. 2010;464(7285):59-65. doi: 10.1038/nature08821.

39. Sagheddu V, Patrone V, Miragoli F, Puglisi E, Morelli L. Infant Early Gut Colonization by Lachnospiraceae: High Frequency of Ruminococcus gnavus. Front Pediatr. 2016;4:57. doi: 10.3389/fped.2016.00057.

40. Schirmer M, Smeekens SP, Vlamakis H, Jaeger M, Oosting M, Franzosa EA, Ter Horst R, Jansen T, Jacobs L, Bonder MJ, Kurilshikov A, Fu J, Joosten LAB, Zhernakova A, Huttenhower C, Wijmenga C, Netea MG, Xavier RJ. Linking the Human Gut Microbiome to Inflammatory Cytokine Production Capacity. Cell. 2016;167(4):1125-1136.e8. doi: 10.1016/j.cell.2016.10.020.

41. Chyan YJ, Poeggeler B, Omar RA, Chain DG, Frangione B, Ghiso J, Pappolla MA. Potent neuroprotective properties against the Alzheimer beta-amyloid by an endogenous melatonin-related indole structure, indole-3-propionic acid. J Biol Chem. 1999;274(31):21937-21942. doi: 10.1074/ jbc.274.31.21937.

42. Kado S, Chang WLW, Chi AN, Wolny M, Shepherd DM, Vogel CFA. Aryl hydrocarbon receptor signaling modifies Toll-like receptor-regulated responses in human dendritic cells. Arch Toxicol. 2017;91(5):2209-2221. doi: 10.1007/ s00204-016-1880-y

43. Banoglu E, Jha GG, King RS. Hepatic microsomal metabolism of indole to indoxyl, a precursor of indoxyl sulfate. Eur J Drug Metab Pharmacokinet. 2001;26(4):235-240. doi: 10.1007/BF03226377.

44. Wu I-W, Hsu K-H, Lee C-C, Sun C-Y, Hsu H-J, Tsai C-J, Tzen C-Y, Wang Y-C, Lin C-Y, Wu M-S. p-Cresyl sulphate and indoxyl sulphate predict progression of chronic kidney disease. Nephrol Dial Transplant. 2011;26(3):938-947. doi: 10.1093/ndt/gfq580.

45. Kim HY, Yoo T-H, Hwang $Y$, Lee GH, Kim B, Jang J, Yu HT, Kim MC, Cho J-Y, Lee CJ, Kim HC, Park S, Lee WW. Indoxyl sulfate (IS)-mediated immune dysfunction provokes endothelial damage in patients with end-stage renal disease (ESRD). Sci Rep. 2017;7(1):3057. doi: 10.1038/ s41598-017-03130-z.

46. Wikoff WR, Anfora AT, Liu J, Schultz PG, Lesley SA, Peters EC, Siuzdak G. Metabolomics analysis reveals large effects of gut microflora on mammalian blood metabolites. Proc Natl Acad Sci. 2009;106(10):3698-3703. doi: 10.1073/ pnas. 0812874106 .

47. Devlin AS, Marcobal A, Dodd D, Nayfach S, Plummer $\mathrm{N}$, Meyer T, Pollard KS, Sonnenburg JL, Fischbach MA. Modulation of a Circulating Uremic Solute via Rational Genetic Manipulation of the Gut Microbiota. Cell Host Microbe. 2016;20(6):709-715. doi: 10.1016/j. chom.2016.10.021.

Conflict of interests. The authors declare no conflict of interests.

Financing. The study was perfomed without external funding.

Conformity with principles of ethics. The study was approved by the local ethics committee.

Information about the authors

Sheibak Vladimir Mikhailovich, PhD, MD (Medicine), Professor, Grodno State Medical University, e-mail: VSheibak@ gmail.com, ORCID: 0000-0001-6829-447X.

Pauliukavets Anastasiya, PhD (Biology), Associate Professor, Grodno Regional Center for Transfusiology, e-mail: anastasiayk@mail.ru, ORCID: 0000-0001-7995-5587. 